\title{
Characterisation of a Complex Thin Walled Structure fabricated by Selective Laser Melting using a Ferritic Oxide Dispersion Strengthened Steel
}

Thomas Boegelein ${ }^{\mathrm{a}, 1}$, Eleftherios Louvis ${ }^{\mathrm{b}, 2}$, Karl Dawson ${ }^{\mathrm{a}}$, Gordon J. Tatlock ${ }^{\mathrm{a}}$, Andy R. Jones ${ }^{\mathrm{a}}$

${ }^{a}$ High Temperature Materials Group, Centre for Materials and Structures, School of Engineering, University of Liverpool, L69 3G, UK

${ }^{b}$ Manufacturing Science and Engineering Research Centre, Centre for Materials and Structures, School of Engineering, University of Liverpool, L69 3G, UK

1 Corresponding author. Tel.: +44 (0) 151 - 795 2273; fax: +44 (0) 151 - 7944675.

E-mail addresses: t.boegelein@liv.ac.uk, thomas.boegelein@web.de (T. Boegelein).

2 Present address: Additive Manufacturing Technology Centre of Excellence, Stryker Orthopaedics, IDA Business \& Technology Park, Carrigtwohill, Co. Cork. Republic of Ireland. 


\begin{abstract}
$\underline{\text { Abstract }}$
Oxide dispersion strengthened (ODS) alloys exhibit superior mechanical and physical properties due to the presence of nanoscopic $\mathrm{Y}(\mathrm{Al}, \mathrm{Ti})$ oxide precipitates, but their manufacturing process is complex. The present study is aimed at further investigation of the application of an alternative, Additive Manufacturing (AM) technique, Selective Laser Melting (SLM), to the production of consolidated ODS alloy components. Mechanically alloyed PM2000 (ODS-FeCrAl) powders have been consolidated and a fine dispersion of Y-containing precipitates were observed in an as built thinwalled component, but these particles were typically poly-crystalline and contained a variety of elements including $\mathrm{O}, \mathrm{Al}, \mathrm{Ti}, \mathrm{Cr}$ and $\mathrm{Fe}$. Application of post-build heat treatments resulted in the modification of particle structures and compositions; in the annealed condition most precipitates were transformed to single crystal yttrium aluminium oxides. During the annealing treatment, precipitate distributions homogenised and localised variations in number density were diminished. The resulting volume fractions of those precipitates were $25-40 \%$ lower than have been reported in conventionally processed PM2000, which was attributed to Y-rich slag-like surface features and inclusions formed during SLM.
\end{abstract}

Keywords: Oxide dispersion strengthened alloys; rapid prototyping; additive manufacturing; selective laser melting; transmission electron microscopy 


\section{Introduction}

Modern ODS alloys have many potential fields of application. However, they were designed for high temperature applications, for instance in conventional power plants or in gas turbines, where an increase in operating temperatures is beneficial [i]. The portfolio of suitable materials decreases rapidly with increase of working temperature. Superalloys are capable of operating at temperatures of $\sim 1000^{\circ} \mathrm{C}$ [ii], but this limit can be extended to up to $1300^{\circ} \mathrm{C}$ for alloys containing an oxide dispersion [iii]. Even higher operation temperatures are possible with ceramics, graphite, refractory metals and advanced thermal barrier coatings, but often their practical use is constrained $\left[{ }^{\mathrm{iv}},{ }^{\mathrm{V}}\right]$.

ODS alloys have been developed over recent decades following the early work by Benjamin [vi] on mechanical alloying (MA) of Ni-base alloys and are fascinating due to their interesting properties. Characteristic of this class of alloys is the presence of a fine dispersion of rare earth metal (typically yttrium) oxide precipitates having diameters of several nanometres. The current manufacturing route for ODS alloys includes MA of master alloys or elemental powder, hot extrusion or hot isostatic pressing (HIP), which can be followed by rolling and a final heat treatment [vii]. Yttrium, which has a very low solubility in alpha-ferrite matrix at room temperature, is typically added to the alloy in the form of yttria $\left(\mathrm{Y}_{2} \mathrm{O}_{3}\right)$ during MA. There is still some debate whether the yttria is broken down and $\mathrm{Y}$ is forced into supersaturated solid solution [viii] or whether yttria just fractures and forms small amorphous compounds $\left[{ }^{\mathrm{ix}}\right]$. During successive consolidation, precipitates evolve in the alloy matrix and grow in diameter during various production steps $[\mathrm{x}]$ and amorphous compounds become crystalline [ix]. The complex metallurgy route used to produce ODS alloys leads to high prices and limitations in the form of consolidated material, which motivates constant research on a number of alternative production routes, such as gas atomization reaction synthesis [xi] or spark plasma sintering [xii]. The excellent high-temperature oxidation resistance displayed by ODS-FeCrAl PM2000 alloy, as used in this study, has been attributed to the presence of yttrium and aluminium [xiii]. The fine precipitate dispersion blocks dislocation motion and the recrystallised microstructure, which is formed due to abnormal grain growth, is extremely coarse [xiv] and beneficial to creep resistance. The special resistance of ODS alloys to radiation induced damage has been investigated by ion implantation studies and evidence suggests that the ultrafine dispersoids can act as sink sites for transmutation He, formed when exposed to neutron irradiation [xv]. For nuclear applications, however, the element $\mathrm{Al}$ needs to be minimised in order to avoid the formation of a long-lasting radioactive isotope and precipitates need to be in the nanometre size range [xv]. Thus, ODS steels are considered as candidate structural materials for both fossil and nuclear energy applications. PM2000 was designed for hightemperature applications [xvi], but its use for biomass combustion [xvii] and medical implants [xviii] has also been considered.

Methods of joining of ODS alloys involving melting, usually result in agglomeration of the dispersoids and in inferior mechanical properties of the bond zone [xix]; however, several solid-state 
joining techniques are currently being investigated with promising results [xx]. An alternative method is laser beam welding and it was shown in several studies that ODS precipitates can be retained in the fusion zone [xix,xxi]. This work uses SLM to consolidate as-MA PM2000 powder, which has certain similarities with laser welding. The technique produces fully dense solid freeform components by successive melting of thin layers, of metal powder (in this work: $50 \mu \mathrm{m}$ ), with a finely focused laser beam. The thermal conditions are similar to conduction based laser welding with typically very high cooling rates and continuous stirring in the melt pool caused by Marangoni-forces [xxii] making SLM of potential use in the ODS alloy environment. More details on the SLM process can be found elsewhere [xxiii]. It was shown recently by Walker et al. that SLM builds grown using as-MA PM2000 powder contain a fine dispersion of precipitates in the alloy matrix and processing parameters can be altered to manipulate the particle size and minimise their degree of agglomeration [xxiv]. Successive work in this field concentrated on ODS alloy coatings, which were well adherent to a substrate even when annealed [xxv,xxvi] and the presence of fine $\mathrm{Al}$ and Y-rich precipitates in the deposit could be confirmed [xxvii]. SLM processing parameters were further optimised to manufacture walls with different thicknesses and solid structures; and it was recently found that after a post-build anneal at $1200^{\circ} \mathrm{C}$ for 1 hour, a room temperature strength, which was comparable to that of conventional recrystallized PM2000, could be achieved [xxiii]. However, the strength was inferior for Fe-base ODS-MA956 produced via a similar process, selective laser sintering (SLS) [xviii]. Processing parameters developed by Walker et al. [xxiv] were used to fabricate the build in this study which is focussed on more detailed characterisation since a profound understanding of SLM-ODS alloy fundamentals is still lacking. This study is part of a larger project investigating the feasibility of using SLM for additive manufacture of near net shape components, by consolidating mechanically alloyed powders from ODS alloys.

\section{$\underline{\text { 2. Materials and methods }}$}

\subsection{Manufacture of SLM builds}

The powder material consolidated in this work was supplied by Plansee GmbH (Reutte, Austria) in the form of as-MA ODS-PM2000. This material is no longer commercially available, but prior to use, the powder material was stored in sealed containers in dry conditions and chemical analysis did not reveal any form of contamination. The nominal composition according to the PM2000 datasheet [xvi] and measurements using inductively coupled plasma optical emission spectrometry (ICP-OES) are displayed in Table 1. In addition to the intended alloying elements, low levels of trace elements were also detected; for example, $\mathrm{Mn}$ and $\mathrm{Ni}$ were measured at 0.05 and 0.02 wt.\% respectively. Other 
elements were measured at concentrations $\leq 0.01 \mathrm{wt} . \%$, although oxygen levels could not be measured by this technique.

The same batch of PM2000 powder, used in this study, has been analysed in greater detail by Walker et al. [xxiv]. The filling factor of the sieved powder was determined as 0.46 , which means that in order to fabricate a consolidated layer of $50 \mu \mathrm{m}$, a $109 \mu \mathrm{m}$ thick slice of powder needs to be scanned. Consequently, before the SLM procedure, the powder material was sieved with a $106 \mu \mathrm{m}$ mesh size stainless steel sieve, in order to remove coarser powder particles. Consolidation was conducted on a SLM machine, type Realizer 100 from ReaLizer GmbH, which was equipped with a YLM-50 ytterbium fibre laser (LPG Photonics) and the maximum laser output power $(50 \mathrm{~W})$ was applied. The wavelength was 1075-1095 $\mathrm{nm}$ and the beam shape was similar to a Gaussian distribution. The beam was focused at the build area and the spot diameter was $\sim 80 \mu \mathrm{m}$. The machine set-up, consisted of a sealed building chamber in which the consolidation process took place under Ar atmosphere with a remaining O concentration of 200-300 ppm prior to building. Oxidation effects with the alloy during processing resulted in a significant reduction of oxygen after the first few layers had been deposited. The inert gas was pumped through a filter system during processing and was redirected through nozzles onto the build space. Scanning was conducted in directions toward the gas stream to minimise re-deposition of ejected material which can affect the consolidation process. Parameters similar to those reported by Walker et al. [xxiv], which produced the fewest oxide agglomerations in the build, were used in this study. The current scan strategy applied four parallel scans per deposit layer to form the wall thickness in order to obtain fully dense structures, but also to investigate the tendency for dispersoid agglomeration during re-melting sequences during growth. For each slice, the two outer lines were scanned first, followed by the inner two, in order to support the formation of dense walls, since powder particles are known to be dragged into the melt pool [xix]. The distance between one outer and the neighbouring inner scan line was $70 \mu \mathrm{m}$, while the distance between the two inner lines was $60 \mu \mathrm{m}$. As presented in Fig. 1, the resulting build was a complex hexagonal shaped wall structure, which was grown on a mild steel substrate on triangular support structures, which eased the removal process.

\subsection{Sample preparation and analytical techniques}

In this study samples, taken from the outer walls, were sectioned using a water-cooled low speed saw. Specimens were chemically cleaned prior to heat treatments, which were conducted in a horizontal tube furnace on silica trays. Although ODS-FeCrAl alloys are known to form protective, slow growing, scales composed of $\alpha-\mathrm{Al}_{2} \mathrm{O}_{3}$ at high temperatures $\left(>\sim 1000^{\circ} \mathrm{C}\left[{ }^{\mathrm{xx}}\right]\right)$, a flowing argon atmosphere was used to protect against excessive oxidation during heat treatment. 
Specimens were prepared for SEM analysis by standard techniques and a final polish was applied using a $40 \mathrm{~nm}$ colloidal silica suspension. Specimens which required etching were polished to a 0.25 $\mu \mathrm{m}$ finish, using diamond paste, prior to immersion in a $10 \% \mathrm{HCl} 90 \%$ methanol solution. SEM work was conducted on a JEOL JSM-7001F field emission gun (FEG) instrument operated at beam energies of 15-30 keV in both secondary electron (SE) and backscattered electron (BSE) modes, respectively. Chemical analyses were performed by energy dispersive X-ray spectroscopy (EDS) on this machine using an INCA x-act-51-ADD0001 EDS system from Oxford Instruments.

Sections of the outer walls were thinned from both sides to a thickness between 100-200 $\mu \mathrm{m}$. Discs $3 \mathrm{~mm}$ in diameter were punched and then ground, applying a 4000 grit finish, to a thickness of $<50$ $\mu \mathrm{m}$. Final thinning to electron transparency was performed on a twin-jet electropolishing system, Tenupol-3 from Struers, in a $10 \%$ perchloric acid in methanol solution at a temperature of $-45 \pm 5^{\circ} \mathrm{C}$. Thin-foil samples from the top layers of the build could not be prepared by this method and were therefore prepared by a lift out method using a FEI Helios Nanolab 600i focused ion beam (FIB) instrument. Dispersoids were extracted onto amorphous C-film after a replica method described elsewhere [xxxi] using a 10vol.\% $\mathrm{HCl}$ in methanol solution as an etchant. TEM imaging and EDS was conducted on a JEOL JEM-3010 instrument equipped with a LaB6 source and an Link ISIS Pentafet detector/amplifier EDS system from Oxford Instruments; the microscope was operated at $300 \mathrm{kV}$.

The size distribution of precipitates was determined from analysing $>200$ randomly chosen particles measured in different grains observed in micrographs recorded at 50,000× magnification. In order to correct for stereological factors of the thin-foil samples, bearing in mind that the precipitate size was relatively high compared to the thickness of the electron-transparent region, the method presented by Wosik et al. [xxxii] was applied. Thickness measurements were acquired from EFTEM thickness maps recorded in a JEOL 2100FCs TEM/STEM, operated at $200 \mathrm{kV}$, fitted with a Gatan Quantum post column energy filter. The mean free path of electrons in PM2000 was calculated using the Mean Free Path Estimator script developed by Mitchell [xxxiii] based on work by Malis et al. [xxxiv] resulting in a value of approx. $70 \mathrm{~nm}$, when using the main alloying elements $\mathrm{Fe}, \mathrm{Cr}, \mathrm{Al}$ and $\mathrm{Ti}$. Both procedures facilitated the determination of the volume fraction of precipitates, which were acquired from several randomly chosen areas of the individual electron-transparent regions at 20,000x magnification. The accuracy of such thickness measurements is known to be within a range of up to $\pm 20 \%$ [ ${ }^{\mathrm{xxx}}$ ], which has been considered in the diagram presented later as the relative error of that analysis.

\section{Results}

\subsection{Surface morphology and microstructure}


The surface finish of the walls of the SLM built walls varied from region to region. One extreme (Fig. 2a) was relatively smooth, but on the other hand there were also zones with an increased number of attached powder particles (Fig. 2b). The occurrence of both types of finishes did not follow a specific pattern and was perhaps influenced by turbulence of the gas stream in different regions of the build space. Another feature of the build surface were micron sized $\mathrm{Y}-\mathrm{Al}$ oxide slag particles which appeared bright in SE images due to the effects of charging.

The slag-like particles were investigated further in cross section and BSE images revealed the presence of several types of feature (Fig. 3a,b). Chemical analysis indicated that these were $\mathrm{Al}_{2} \mathrm{O}_{3}$ (alumina, Fig. 3c) and $\mathrm{Y}_{3} \mathrm{Al}_{5} \mathrm{O}_{12}$ (yttrium-aluminium garnet - YAG, Fig. 3d), respectively. The features often showed a dendritic and lamella-shaped appearance, suggesting they had solidified from the melt; occasionally nodules, which displayed a similar microstructure, were incorporated into the consolidated alloy as inclusions.

The concentration of alloying elements detected in both the $\mathrm{O}, \mathrm{Al}$ and Y-rich slag and inclusions, relative to their concentration in the raw powders, was determined by calculations of EDS area scans and measuring individual area fractions of particles in wall cross sections. Proportional calculations were applied to determine atomic percentages and details of this study are given in [xxvii]. The mean values of tests of numerous individual nodules and inclusions are shown in Table 2. For this work, regions of the sample lengths of $1 \mathrm{~mm}$ from the top and bottom of the build were analysed. Approximately $25-30 \%$ of the Y, originally included in the as-MA powder, was lost to slag/ inclusions during the build. The volume fraction of such Y-rich material was $0.6-0.7 \%$ of the overall metal volume. It is interesting to note that that the sum total of $\mathrm{O}$ in all the particles included more $\mathrm{O}$ than available from the original yttria addition. As discussed in more detail later (§4.2), this suggests that the $\mathrm{O}, \mathrm{Al}$ and $\mathrm{Y}$-rich structures are perhaps the remains of partly re-melted oxide scales formed during deposition, or oxides in the as-MA powder, rather than agglomerated and slagged-off ODS precipitates. Indeed, agglomerations of precipitates were not observed during this study.

Re-melting of the previously deposited layers, plus epitaxial growth led to long columnar grain structures being formed, oriented strongly along the growth direction. Other work on SLM-PM2000 builds [xxiii] has also shown that grains grow along the <001> "easy-growth" direction of body centred cubic metals [xxxvi] in a "fibre-textured" fashion.

1 in 3 of the outer walls showed some cracking along the growth direction with individual cracks of up to $1.5 \mathrm{~cm}$ in length and typically up to three cracks per wall. SEM performed on etched cross sections of the configuration (Fig. 4a) revealed that intergranular cracking, caused by residual stresses in the build, was apparent. The crack surface shown in Figs. 4b,c revealed bright inclusions containing $\mathrm{O}, \mathrm{Al}$ and $\mathrm{Y}$, which probably acted as weak points (see discussion $\S 4.3$ ). 


\subsection{Studies on dispersoids contained in the as-grown condition}

Of profound interest is the presence of a fine dispersion of ODS particles in the build which were studied using TEM-techniques on thin-foils taken from as-grown samples. Two micrographs at different magnification are displayed in Fig. 5. As mentioned before, agglomerations of particles or significant variation in number density between different grains were not observed. Grain boundaries were not found to be preferred nucleation/growth sites of precipitates. Dislocations were also evident and hence interacted with the particulates. Fig. $5 \mathrm{~b}$ shows this situation in a tilt orientation leading to a strong diffraction contrast of dislocations.

The size distribution of precipitates was determined from micrographs chosen randomly over the electron-transparent region of the sample. Particle diameters as small as $10 \mathrm{~nm}$ were analysed, which are included in a diagram of the relative size distributions presented in Fig. 6. As is evident from the diagram, particles were finer than conventional recrystallized PM2000 with a main peak in the diameter range of 25-30 $\mathrm{nm}$. The diagram also includes the particle size distribution after an isothermal heat treatment at $1200^{\circ} \mathrm{C}$ for $1 \mathrm{~h}$, which will be discussed in $\S 3.4$.

HRTEM and EDS studies were conducted on extracted precipitates. One major finding was that smaller dispersoids of the as-grown condition showed a high degree of poly-crystallinity. Fig. 7a,b displays micrographs of a typical small particle in two different focal positions. The studies indicated also that the size of individual areas having a different structure decreased with an increase in particle diameter as presented in Fig. 7c. EDS analyses of extracted precipitates revealed particles which contained several elements including $\mathrm{O}, \mathrm{Al}, \mathrm{Ti}, \mathrm{Cr}, \mathrm{Fe}$ or $\mathrm{Y}$. The presence of traces of $\mathrm{Si}$ in such compounds could not be investigated due to a near-peak overlap of Si-K $\alpha$ with a strong Y-L $\alpha 1$ peak. $\mathrm{Si}$ has a trace concentration of $0.02 \mathrm{wt} . \%$ in the as-MA powder according to the analysis by ICP-OES. Future studies should consider this fact and utilise additional techniques, for instance APT or electron energy loss spectroscopy (EELS) to investigate the presence of traces of Si. It was confirmed by TEMEDS in different regions of particles that the elemental composition varied depending on the location within the particle. Core-shell structures, however, were not observed.

Fig. 8 displays the elemental composition for $\mathrm{Al}, \mathrm{Ti}, \mathrm{Cr}, \mathrm{Fe}, \mathrm{Y}(\mathrm{Al}+\mathrm{Ti}+\mathrm{Cr}+\mathrm{Fe}+\mathrm{Y}=100$ at.\%) of randomly chosen precipitates of the extraction replica fabricated from the centre of a wall. At this stage we would like to acknowledge that this replication technique might lead to sampling differences in terms of particle size/type distribution, crystallographic or compositional changes. The EDS analysis of particles with diameters below $\sim 22 \mathrm{~nm}$ was also strongly affected by signal noise due to the small size of the dispersoids and such measurements should be treated with care. However, it was evident that the concentration of $\mathrm{Al}$ and $\mathrm{Y}$ increased with increasing particle diameter, whereas $\mathrm{Ti}, \mathrm{Cr}$ and Fe decreased. Overall, there was also a large variation in the elemental composition from particle to particle. The diagrams show elemental concentrations measured for Y-Al oxides, which were 
extracted from annealed specimens. In particular, the lines displayed represent the compound types yttrium aluminium monoclinic (YAM), having a sum formula of $\mathrm{Y}_{4} \mathrm{Al}_{2} \mathrm{O}_{9}$, and $\mathrm{YAlO}_{3}$, which forms the known polymorphs yttrium aluminium hexagonal (YAH), yttrium aluminium perovskite (YAP) and YAP'. This latter type has only been described rarely in literature [ ${ }^{\mathrm{xx} x v i i}$, $x x$ xviii]. A match of particles in the as-grown condition with the individual elemental concentrations of these compounds could not be observed, however.

\subsection{Studies of annealed specimens}

A post-build annealing treatment at $1200^{\circ} \mathrm{C}$ for 1 hour of the samples taken from walls resulted in a reduction of the dislocation density, but a fine dispersion of precipitates was retained, as displayed in Fig. 9a,b. There was also a significant change in the relative particle size, as shown in Fig. 5. The main peak of the distribution was between 10-15 nm and a secondary peak was apparent between 30-50 nm.

HRTEM on extracted particles of the annealed build revealed that the individual lattice structures became significantly modified during the heat treatment into predominantly single-crystalline precipitates. Figs. 10a,b illustrate this for a small and a medium sized particle, respectively. In addition, 1 in 40 particles contained more than one phase - typically two or three - as indicated by different lattice structures within the particles, although they still retained their globular shape (Fig. $10 \mathrm{c})$.

The annealing treatment of the material significantly affected the elemental composition of the particles, as determined from analyses of extracted particles, displayed in Fig. 11. After heat treatment, most particles were composed purely of $\mathrm{Y}, \mathrm{Al}$ and $\mathrm{O}$. The ratio of the elements $\mathrm{Al}$ and $\mathrm{Y}$ fell within two main groups, one with a good fit to $\mathrm{Y}_{4} \mathrm{Al}_{2} \mathrm{O}_{9}$ (YAM) and one with a composition which would indicate $\mathrm{YAlO}_{3}(\mathrm{YAH}, \mathrm{YAP}$ or YAP'). It should also be noted that traces of Si were detected in some cases in this latter precipitate type. Since the Si concentration was far below that of Y, quantification was not possible, with peak overlaps of Si-K $\alpha$ with a strong Y-L $\alpha 1$ peak in the EDS spectra. Above a particle diameter $\sim 25 \mathrm{~nm}$ there was no strong size/type relationship. Below this value, however, the determination of the elemental composition was affected by signal noise, but the Y/Al ratio was closer to the $\mathrm{Y}_{4} \mathrm{Al}_{2} \mathrm{O}_{9}$-type. Occasionally, there were particles which did not follow this pattern (*), which might be a precipitate consisting of more than one crystal including both a $\mathrm{Y}_{4} \mathrm{Al}_{2} \mathrm{O}_{9}$ and a $\mathrm{YAlO}_{3}$-type compound.

Approximately 1 in 40 dispersoids were assigned as $\mathrm{TiC}$; details on this can be found elsewhere [xxvii]. Often, such compounds were connected with globular Y,Al-rich precipitates as displayed in bright field mode in Fig. 12a and in dark field mode (diffraction contrast) in Fig. 12b. As will be discussed in sub-section 4.3, this may indicate that they were formed out of originally mixed particles during the annealing treatment. 


\subsection{A study on the evolution of the volume fraction of precipitates}

The upper layer of the SLM structure represents the zone with least heat input during SLM processing of the honeycomb structure and the material deeper in the consolidated material experienced an increased number of repeated heating cycles during processing. Consequently, this region can be used to study precipitate evolution.

The volume fraction of precipitates was studied in four different areas of the specimen using micrographs recorded at intermediate $(20,000 \times)$ magnification; the results are displayed in Fig. 13. For the as-grown condition, it was evident that this fraction varied strongly between $\sim 0.010$ and 0.015 in the top region and similarly in the centre position. The presence of $\mathrm{Y}$ in precipitates close to the wall could be confirmed by EDS. This suggests that precipitates experience no significant modifications when moving deeper into the material. The annealing treatment reduced the volume fractions to values of $\sim 0.006$ and also the variability between different areas was significantly lower. Compared to conventionally produced PM2000 [xxxix], this value was $\sim 25 \%$ to $\sim 40 \%$ lower than fine grained (average grain size: $\sim 24.7 \mu \mathrm{m}$ ) and coarse grained (average grain size: $\rightarrow \infty$ ) material, respectively.

\section{Discussion}

\subsection{Development and evolution of dispersoids}

During this study, there was no evidence that grain boundaries acted as the preferred nucleation sites for oxide particles and precipitates were never agglomerated. Therefore, it is suggested that there are initial ultrafine precipitates, surviving MA and melting, which act as nuclei for precipitate formation. On such nuclei, depending on their chemical affinity, $\mathrm{Ti}, \mathrm{Al}, \mathrm{Cr}, \mathrm{Fe}$ and Y-based compounds may easily nucleate and grow. It appears that this happens in the initial stages of deposition in liquid metal and/or in the solidified matrix since the volume fraction of precipitates is similar near the wall top and deeper in the material. The variations in volume fractions in different regions may be explained by the fact that, due to the laser melting process, there are regions with a different thermal history during growth in one sample. On the other hand, the chemical composition of initial nuclei may be inhomogeneous, attracting growth of certain compound types. Heating during deposition, but also during post-build annealing emphasised later, increases the mobility of $\mathrm{Y}$ in the matrix significantly since the diffusion velocity of $\mathrm{Y}$ in an $\alpha$-Fe matrix at low temperatures is very low $\left.{ }^{[\mathrm{x}}\right]$. Al-Y-O are probably the most chemically stable compounds in the PM2000 alloy system and 
other elements present in the dispersoids before the heat treatment ( $\mathrm{Ti}, \mathrm{Cr}, \mathrm{Fe}$, etc) simply diffuse into the alloy matrix, during heat treatment and reduce the size of the dispersoids. Since multiple layers of PM2000 were deposited, material also re-melts and the Al-Y-O particles are retained and can coarsen. Overall this explains the observation that the larger precipitates in the as-grown condition contain increased concentrations of $\mathrm{Al}$ and $\mathrm{Y}$.

In the as-grown condition, a certain amount of $Y$ may still be in solid solution in the alloy matrix or present in the form of nanoscopic clusters. During post-build annealing, nucleation/growth of new particles may occur incorporating this $\mathrm{Y}$, whereas other particles are subject to phase changes $\left[{ }^{\mathrm{xl}}\right]$ and may also coarsen. The formation of the Al-Y rich oxides from the multi-phase particles may release $\mathrm{Ti}$ and $\mathrm{C}$ forming TiC particles. Indications for this were that they were often connected with globular Al-Y-O. Ti(C,N) was also observed in conventional PM2000 by other researchers [xiv, ${ }^{x l i}$ ]. Ti containing ODS particles or yttria $\left(\mathrm{Y}_{2} \mathrm{O}_{3}\right)$ nanoparticles found in other nuclear-type (Al-free) ODS steels [xliii, xliv] were not observed during the present work and this is consistent with other studies on Al-containing ODS steel [xlii, ${ }^{x l v}$, xlvi]. A stronger chemical affinity of $\mathrm{O} / \mathrm{Al} / \mathrm{Y}$ rather than $\mathrm{O} / \mathrm{Ti} / \mathrm{Y}$ or $\mathrm{O} / \mathrm{Y}$ is believed to be the mechanism responsible.

\subsection{Y-rich segregations}

Micron sized $\mathrm{O}, \mathrm{Al}$ and Y-rich particles were present, both on the wall surface and also in the form of internal inclusions. The two most dominant types of individual features were investigated by EDS. Low-z, facetted particles were probably $\mathrm{Al}_{2} \mathrm{O}_{3}$. The second structure type also displayed a facetted morphology but EDS measurements indicated a composition of approximately $\mathrm{Y}_{3} \mathrm{Al}_{5} \mathrm{O}_{12}$; hence these were probably cubic garnet structured compounds (YAG). It is likely that the yttrium contained in these features resulted in the lower precipitate volume fractions measured in the annealed SLM material compared to conventionally produced PM2000. The amount of oxygen measured in the particles and precipitates was greater than should have been present in the alloy as a whole. This suggests that the yttria addition made during the MA processing stage was not the sole source of oxygen in the SLM builds. Consequently, as SLM processing initially reduces the amount of O in the building chamber, but the volume fraction of micron sized $\mathrm{O}, \mathrm{Al}$ and $\mathrm{Y}$-rich particles was similar near the wall top and base, there must be another, continuous source of oxygen; for instance moisture in the metal powder, trapped air between powder particles in the powder container, O pick-up during MA or leakage into the building chamber. It is also well known that, providing there is a sufficient concentration in the metal, the more reactive elements oxidise preferentially [xlvii], which may explain the different species observed. For example, since yttrium has a greater thermodynamic affinity for oxygen than aluminium, yttrium rich oxides should form first. As yttrium becomes 
exhausted from the local vicinity, kinetics begins to dominate the reactions and aluminium rich compounds are then formed.

A slightly higher volume fraction of both surface nodules and inclusions in the top zone, compared to the base, may be caused by lower temperatures close to the base plate, or a greater cooling rate at the beginning of the SLM process. Material would be molten/heated for a shorter time at the beginning of the deposition process causing a lower volume of scale formation. As indicated by a rapid decrease of the $\mathrm{O}$ content in the building chamber during the early stages of processing, continuous oxidation might take place near the fusion zone, leading to the formation of a scale on the melt pool as was, for instance, observed when SLM processing of $\mathrm{Al}$ alloys [xlviii]. A similar scale might also form near the fusion zone during growth of the present structure. Due to continuous stirring effects in the melt pool described earlier, O-Al-Y-rich material formed might break, float, agglomerate and even partly melt with the formation of eutectic phases. Similar oxidation losses of $\mathrm{Y}$ have been reported previously during the melting process, prior to gas atomisation of an Al-free ODS steel [xi].

\subsection{Cracking}

The SLM deposition process involves large thermal gradients, which induce unwanted residual thermal stresses. They degrade the mechanical properties and can lead to plastic deformation and hence deviations from the intended shape [ $\left.{ }^{\text {xlix }},\right]$. Such high residual stresses may lead to crack propagation along grain boundaries, reducing the load bearing area. Sharp edges of inclusions may also act as crack initiation points as was demonstrated on non-spherical pores in structures produced via laser beam deposition (LBD) [li]. Provided that the bond between inclusions and the metal is weaker than the intermetallic bonds, a similar effect can be expected to be present in this material. One indication of this was the high number of inclusions present on the fracture surfaces. It was not possible to determine if all cracking occurred during processing, on cooling or during removal of the part from the base plate. However, cracks could be observed on the configuration still attached to the substrate. Previous work on other alloys which have high strength at elevated temperatures, such as $\gamma^{\prime}$ containing Ni alloys [lii], demonstrated the link between thermal stress on cooling and the lack of compliance over a range of temperatures. It has also been shown that residual stresses during growth can be effectively reduced by pre-heating the build substrate [xlix,l], re-scanning of layers using reduced laser energy [xlix,l] or by conducting scanning of large areas in the form of small individual 'islands' or 'chess board' patterns [lii, $\left.{ }^{1 i i i}\right]$. On the other hand, post-build annealing can reduce residual stresses [1], whereas hot isostatic pressing was shown to be an effective way to close internal cracks [lii]. The cracking observed is detrimental to mechanical performance; and current work is concentrated on techniques to avoid such build defects in the present material configuration. 


\subsection{Future work}

In order to systematically develop SLM processing parameters for ODS alloys, a thorough understanding of precipitate evolution and transformation sequences are essential. Investigation of ODS powder consolidated by single spots deposited on a ODS-free substrate, might be a further means to achieve this. Characterisation of walls grown using just one single laser scan per layer might reveal further details of the evolution of the particles. APT would be an excellent method to investigate the presence of nanoscopic clusters and the chemical composition of polycrystalline particles. In parallel to the optimisation of processing parameters, future work might also cover ODS alloy development directly for the SLM process to produce solid structures having fine dispersoids. For instance, controlled additions of group 4 elements ( $\mathrm{Ti}, \mathrm{Zr}, \mathrm{Hf}$, La) might be investigated, since these are known to result in finer precipitates of complex oxides with Y [liv,lv,lvi].Certain alloy additions can also increase the fluidity of the melt pool, facilitating the easy manufacture of fully dense SLM builds over a wide range of processing parameters.

\section{Conclusions}

The characterisation of walls with a complex hexagonal structure, grown from as-MA PM2000 powder using the SLM process, has been investigated. The build parameters were developed in a previous study and resulted in the minimum coarsening of precipitates and avoided particle agglomeration. In this study we applied four such scans in parallel, per layer deposited, and concentrated on the transformation of the nanoscopic precipitates, which has not been investigated before.

The findings show that globular precipitates were apparent in the alloy matrix of as-built material. The volume fraction of precipitates did not change significantly during successive growth. However, precipitates were not distributed homogeneously; this was probably associated with different localised thermal conditions experienced during manufacture or an inhomogeneus distribution as well as chemical composition of nuclei. The build was grown with four parallel laser scans per layer deposited, which did not lead to significant agglomeration of precipitates. Their size distribution was similar to conventionally produced recrystallised PM2000. Precipitates were multi-phased in the asgrown condition containing a number of elements, such as $\mathrm{O}, \mathrm{Ti}, \mathrm{Al}, \mathrm{Fe}, \mathrm{Cr}$ and $\mathrm{Y}$. We propose that different compounds nucleate and grow on each other forming the structures observed.

An annealing step conducted at $1200^{\circ} \mathrm{C}$ for 1 hour led to the transformation of these poly-crystalline particles into mainly single-crystalline Y-Al-O precipitates, which represented probably the most stable configuration. The measured $\mathrm{Y} / \mathrm{Al}$ ratios could be explained by the presence of $\mathrm{Y}_{4} \mathrm{Al}_{2} \mathrm{O}_{9}$ and 
$\mathrm{YAlO}_{3}$ compounds. A reduction and stabilisation of the volume fraction of the precipitates during the annealing step was observed. However, 25-30 at.\% of the original Y included in the alloy after MA was shown to form a slag. The post-build heat treatment resulted in an increase in the number density of small $(5-15 \mathrm{~nm})$ dispersoids. This finding can be explained by the nucleation/growth of new, fine precipitates during the anneal which incorporate $\mathrm{Y}$, which is still in solid solution in the as-grown state. A reduction of the particle diameters may also occur during transformation of poly-crystalline multicomponent species into single-crystalline Y-Al-O. The larger particles may also coarsen during this anneal.

Negative aspects of the build were defects (intragranular cracking, inclusions, porosity, poor surface finish) and a loss of $\mathrm{Y}$ (slagging), which suggests a need for further optimisation of the build conditions.

\section{Acknowledgements}

The authors are grateful for financial support of the work through the Advanced Research Materials (ARM) Programme, U.S. Department of Energy, Office of Fossil Energy managed by U.T.-Battelle, LLC and funding by EPSRC grant EP/H018921/1 (Materials for Fusion and Fission Power). The staff at the Nanoinvestigation Centre at Liverpool (NiCaL), led by Dr. S. Romani, is greatly acknowledged for support and helpful advice. The hexagon structure was produced in the Manufacturing Science and Engineering Research Centre at the University of Liverpool, led by Dr. C.J. Sutcliffe. Members of the group, in particular Dr. J. Singh and Dr. J. Robinson, gave valuable input.

\section{$\underline{\text { References }}$}




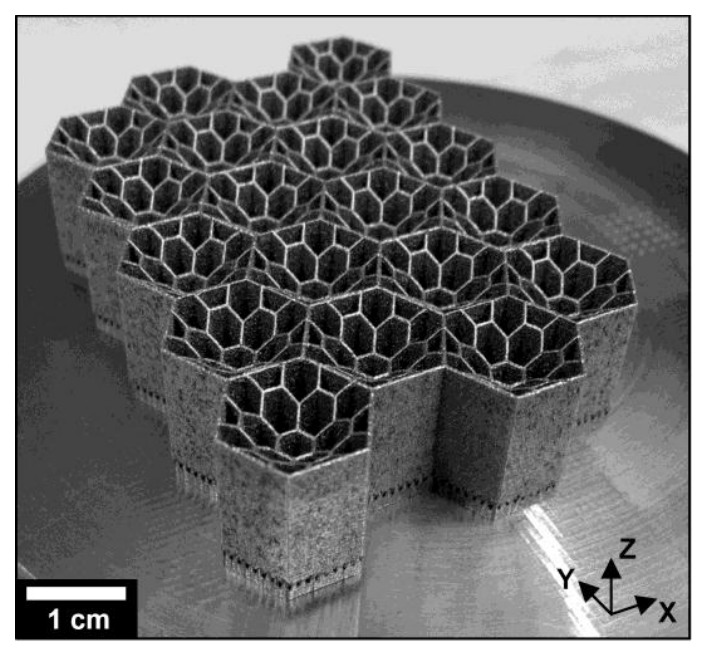



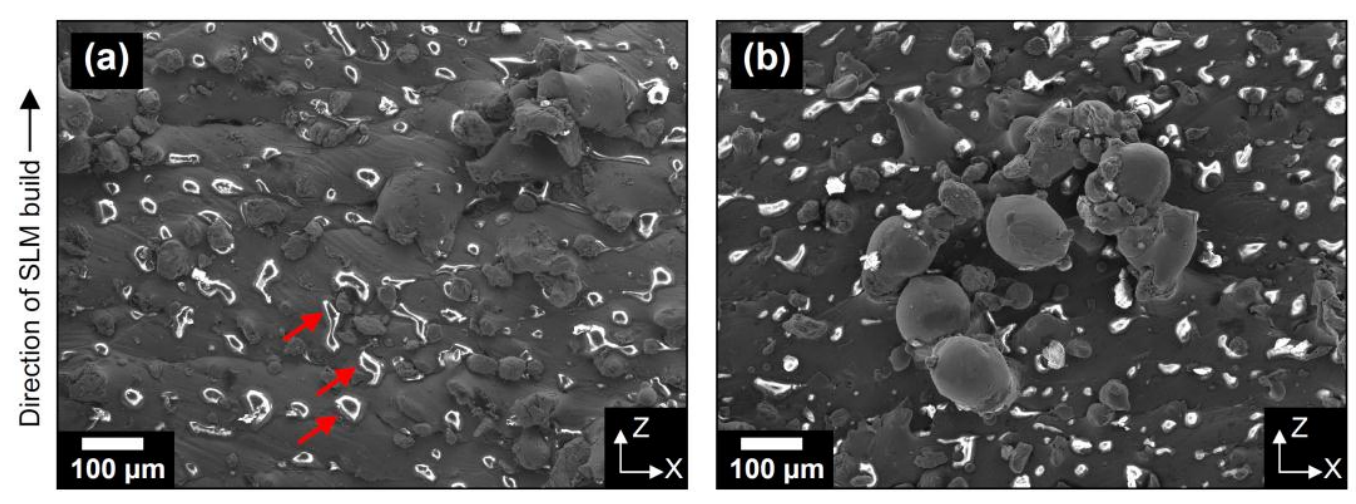


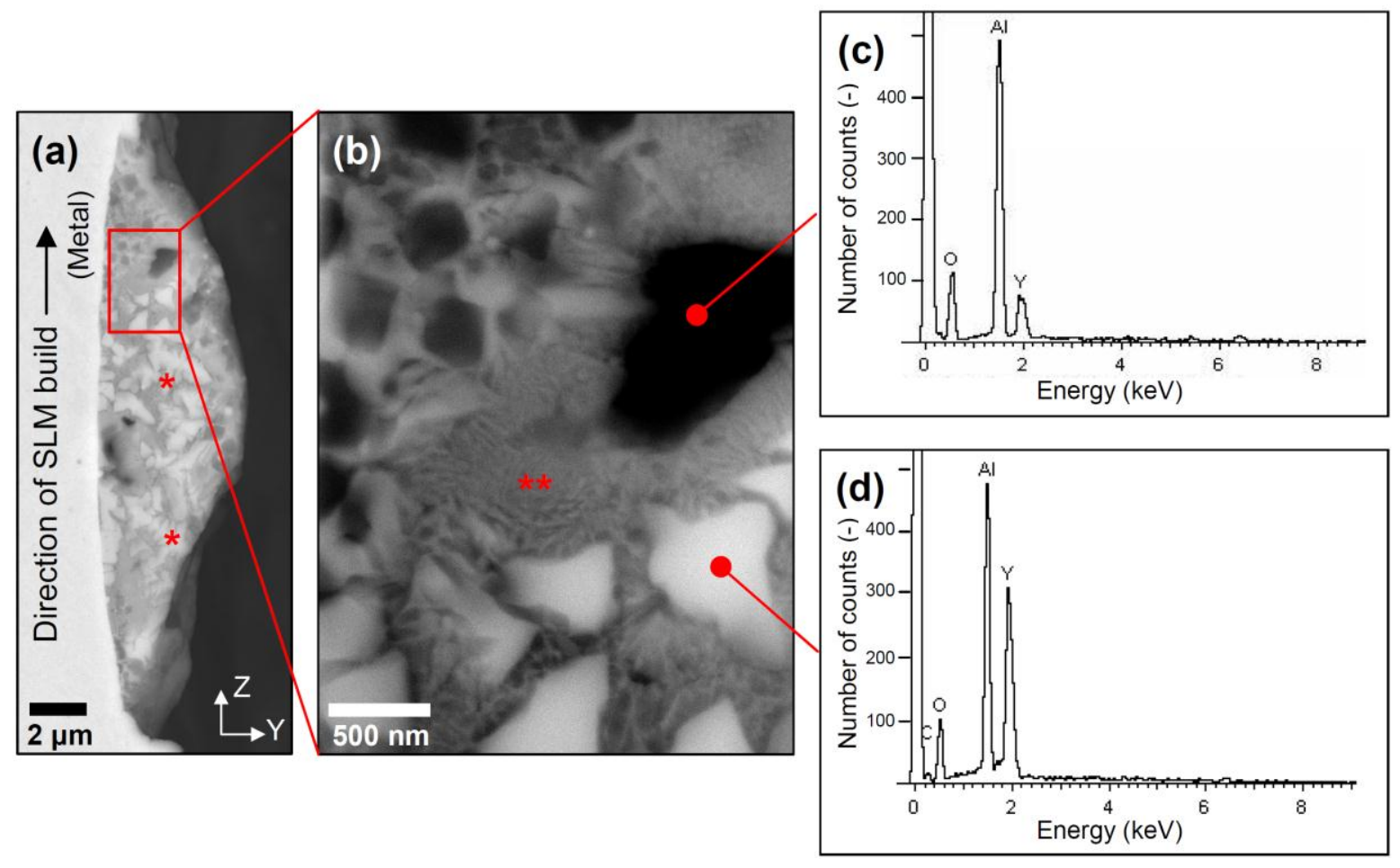




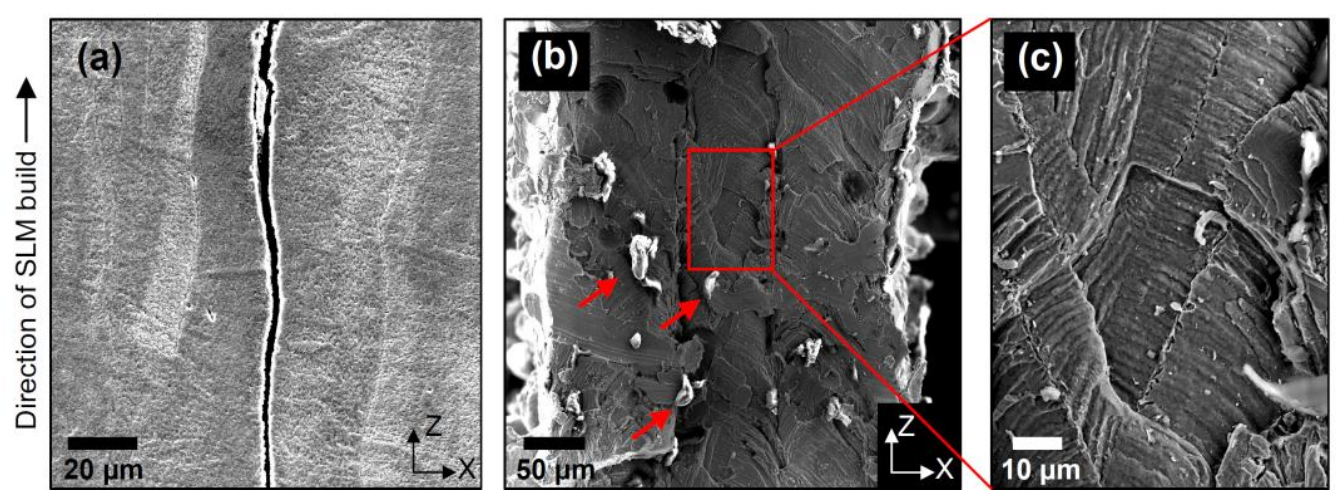




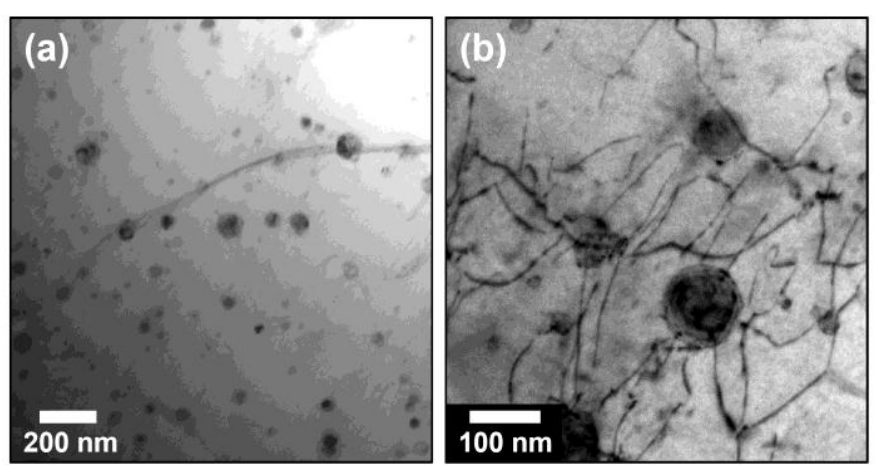




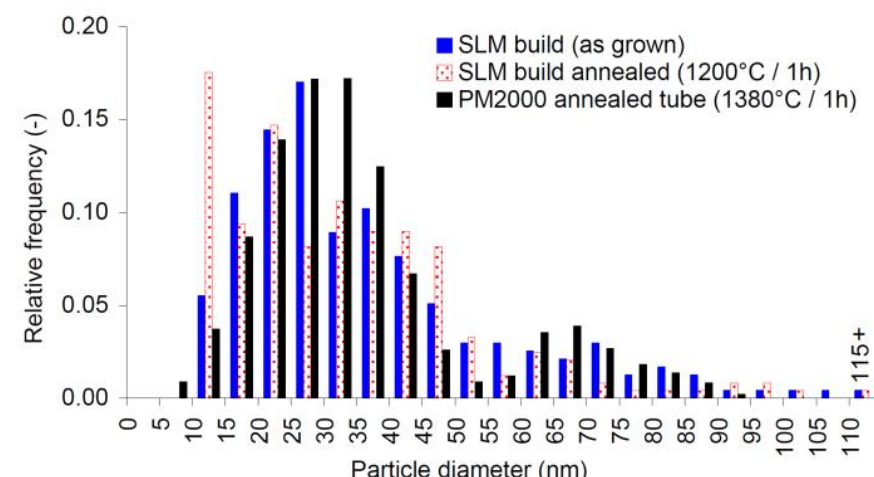



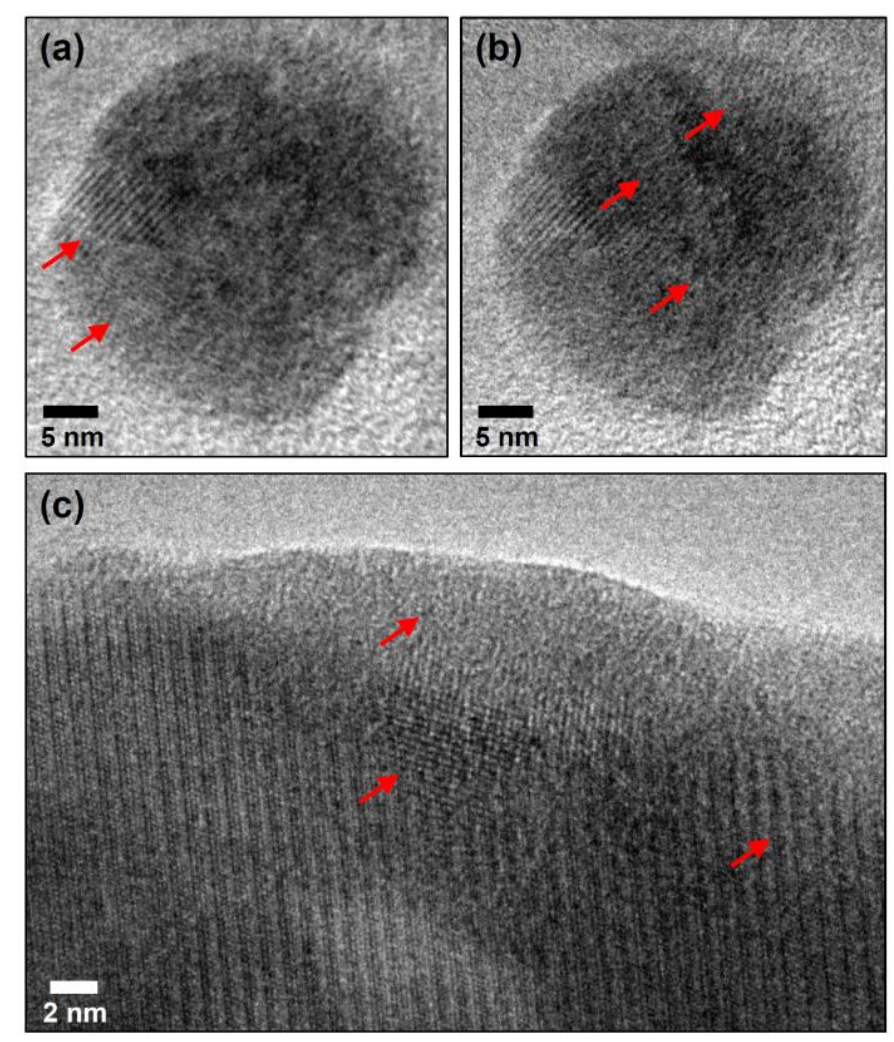

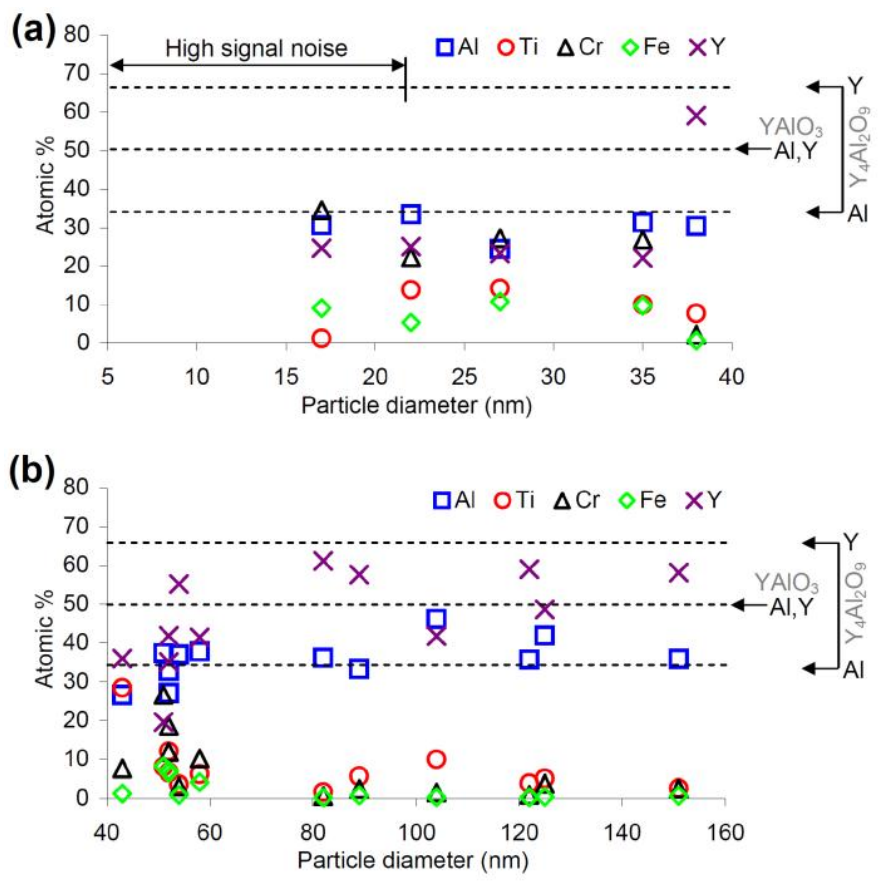


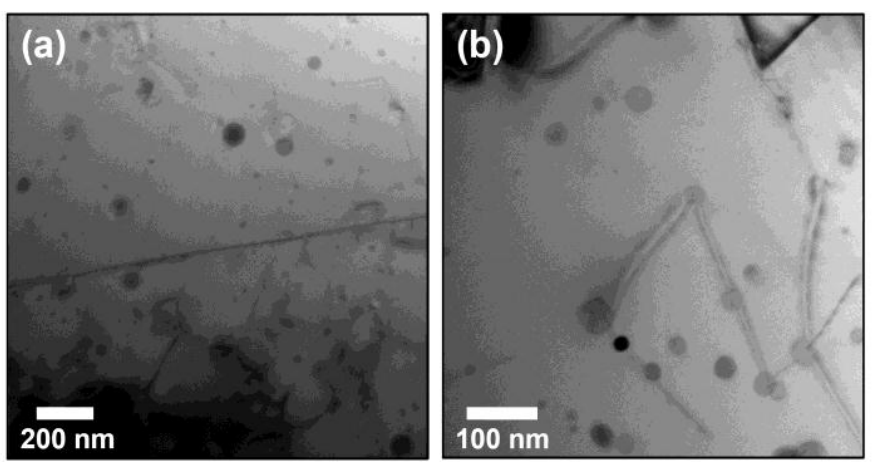



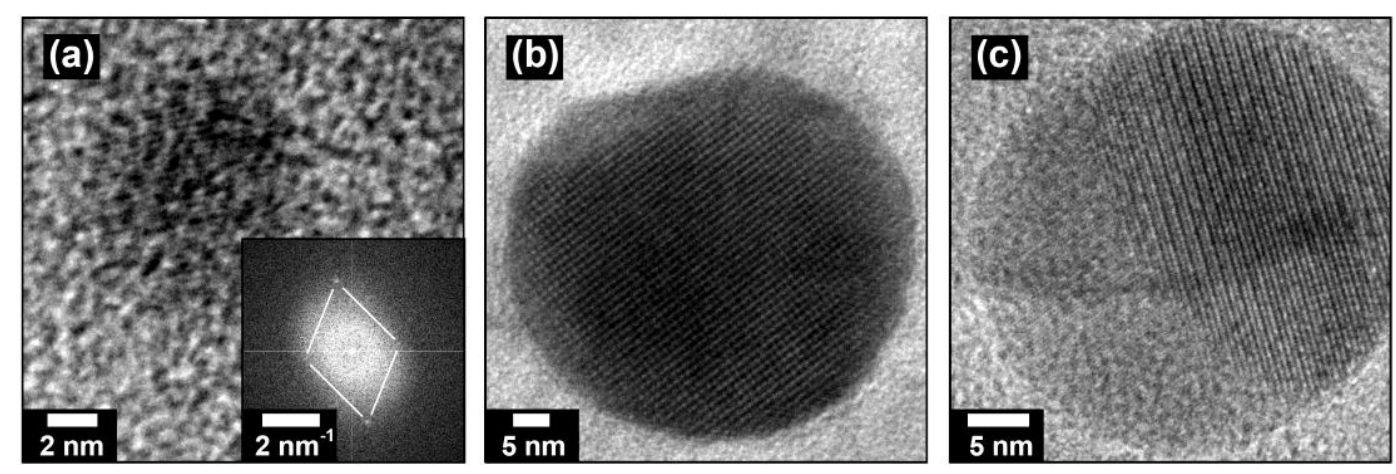
(a) 80

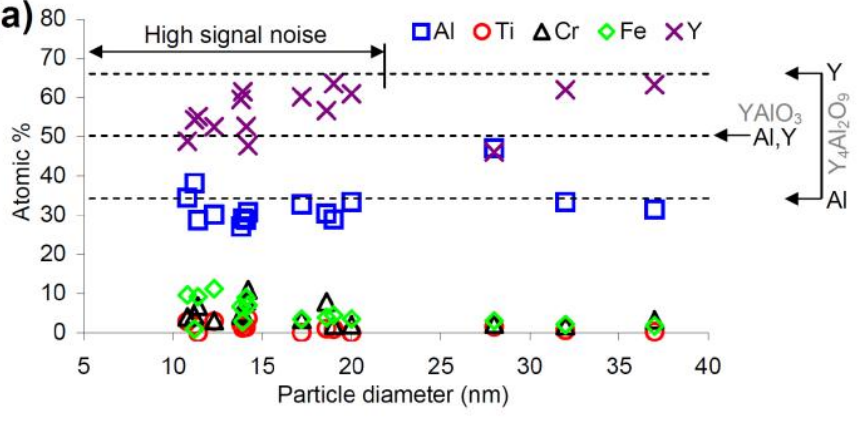

(b)

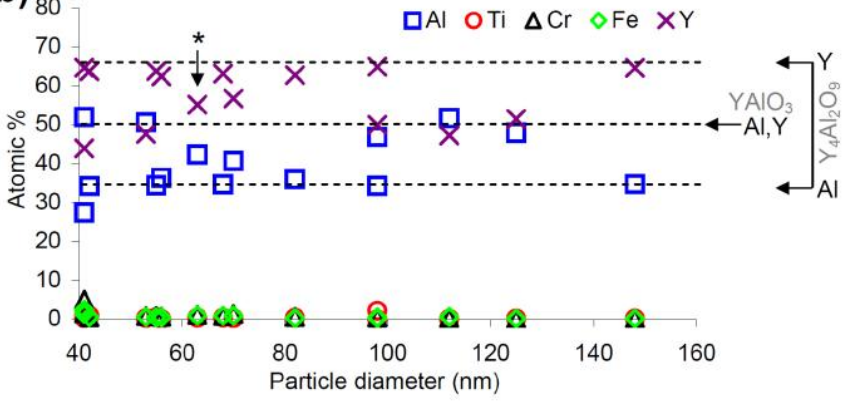




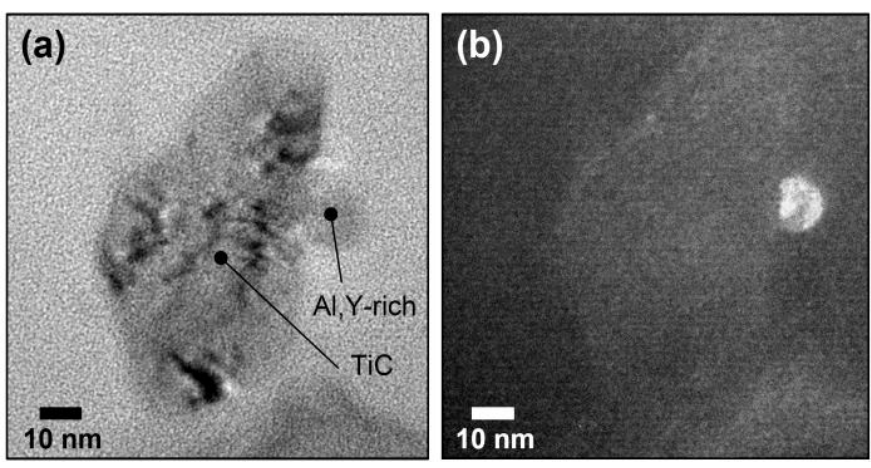




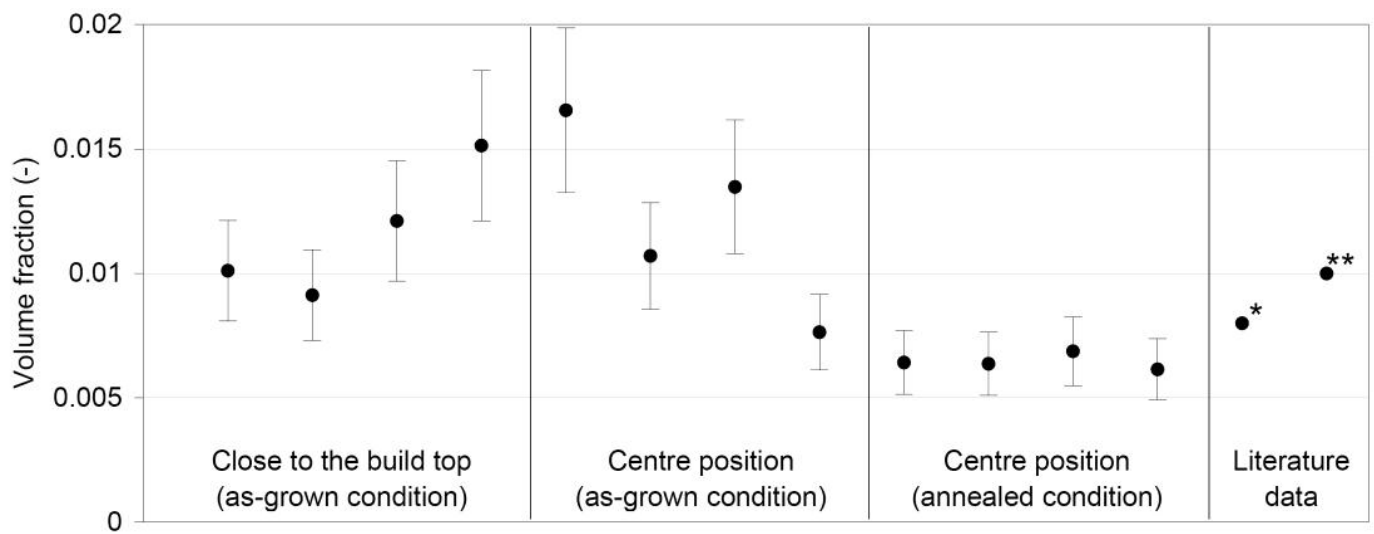




\begin{tabular}{lllllllll}
\hline & $\mathrm{Fe}$ & $\mathrm{Al}$ & $\mathrm{Ti}$ & $\mathrm{Cr}$ & $\mathrm{Y}_{2} \mathrm{O}_{3}$ & $\mathrm{Y}$ & $\mathrm{O}$ & others \\
\hline $\mathrm{A}$ & balance & 5.5 & 0.5 & 19.0 & 0.5 & - & - & - \\
\hline $\mathrm{B}$ & balance & 5.34 & 0.45 & 18.77 & - & 0.39 & 0.24 & $<0.15$ \\
\hline
\end{tabular}




\begin{tabular}{llll}
\hline & Al & O & Y \\
\hline Near the top of the build & 1.9 & 108.3 & 33.0 \\
\hline Near the bottom of the build & 1.7 & 93.9 & 25.3 \\
\hline
\end{tabular}

[i] J.M. Beér (2007). High efficiency electric power generation: The environmental role. Progress in Energy and Combustion Science 33, 107-134, http://dx.doi.org/10.1016/j.pecs.2006.08.002.

[ii] J.R. Davis (2000). Nickel, Cobalt and Their Alloys, Metals Park OH: ASM International, ISBN 0-87170-6857.

[iii] B.A. Pint (1996). Experimental observations in support of the dynamic-segregation theory to explain the reactive-element effect. Oxidation of Metals 45(1-2), 1-37, http://dx.doi.org/10.1007/BF01046818.

[iv] J. Wang, N. Jiang, H. Jiang (2006). The high-temperatures bonding of graphite/ceramics by organ resin matrix adhesive. International Journal of Adhesion and Adhesives 26(7), 532-536, http://dx.doi.org/10.1016/j.ijadhadh.2005.07.005.

["] T.E. Tietz, J.W. Wilson (1965). Behavior and Properties of Refractory Metals. Edward Arnold (publishers) Ltd., ASIN: B0007E2Y5I.

[ $\left.{ }^{\mathrm{vi}}\right]$ J.S. Benjamin (1970). Dispersion Strengthened Superalloys by Mechanical Alloying. Metallurgical Transactions 1(10), 2943-2951, http://dx.doi.org/10.1007/BF03037835.

[vii] H.K.D.H. Bhadeshia (2000). Mechanically alloyed metals. Materials Science and Technology 16, 14141411, ISSN 02670836.

[viii] H. Zhang, M.J. Gorley, K. Boon Chong, M. E. Fitzpatrick, S.G. Roberts, P.S. Grant (2014). An in situ powder neutron diffraction study of nano-precipitate formation during processing of oxide-dispersionstrengthened ferritic steels. Journal of Alloys and Compounds 582, 769-773, http://dx.doi.org/10.1016/j.jallcom.2013.08.069.

$\left[{ }^{i x}\right]$ L. Hsiung, M. Fluss, S. Tumey, J. Kuntz, B. El-Dasher, M. Wall, B. Choi, A. Kimura, F. Willaime, Y. Serruys (2011). HRTEM study of oxide nanoparticles in K3-ODS ferritic steel developed for radiation tolerance. Journal of Nuclear Materials 409, 72-79, http://dx.doi.org/10.1016/j.jnucmat.2010.09.014.

[x] C.A.Williams, P. Unifantowicz, Z. Oksiuta, N. Baluc, G.D.W. Smith, E.A. Marquis (2011). Atom probe tomography analysis of Ti-Y-O clustering during the formation of nanoscale oxide particles in $14 \% \mathrm{Cr}$ ODS ferritic steels. Materials Research Society Symposium Proceedings 1298, 15-20, http://dx.doi.org/10.1557/op1.2011.328.

[ $\left.{ }^{x i}\right]$ J.R. Rieken, I.E. Anderson, M.J. Kramer, G.R. Odette, E. Stergar, E. Haney (2012). Reactive gas atomization processing for Fe-based ODS alloys. Journal of Nuclear Materials 428(1-3), 65-75, http://dx.doi.org/10.1016/j.jnucmat.2011.08.015.

[ $\left.{ }^{x i i}\right]$ S. Pasebani, A.K. Dutt, J. Burns, I. Charit, R.S. Mishra (2015). Oxide dispersion strengthened nickel based alloys via spark plasma sintering. Materials Science \& Engineering A630, 155-169, http://dx.doi.org/10.1016/j.msea.2015.01.066.

[xiii] B.A. Pint (1996). Experimental observations in support of the dynamic-segregation theory to explain the reactive-element effect. Oxidation of Metals 45(1-2), 1-37, ISSN 0030770X. 
${ }^{\left[{ }^{x i v}\right]}$ G. Pimentel, K. Dawson, E. Urones-Garrote, M.M. Aranda, G.J. Tatlock, C. Capdevila, M.K. Miller (2015). HAGBs characterization during the recrystallization process of a Fe-20Cr-6Al ODS alloy. Submitted for review to Materials Characterization.

$\left.{ }^{\left[{ }^{\mathrm{x}}\right]}\right]$ K. Yutani, H. Kishimoto, R. Kasada, A. Kimura (2007). Evaluation of Helium effects on swelling behavior of oxide dispersion strengthened ferritic steels under ion irradiation. Journal of Nuclear Materials 367-370, 423427, http://dx.doi.org/10.1016/j.jnucmat.2007.03.016.

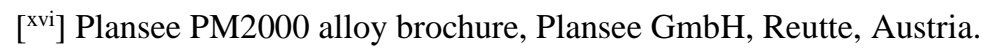

${ }^{\left[{ }^{x v i i}\right]}$ C. Capdevila, U. Miller, H. Jelenak, H.K.D.H. Bhadeshia (2001). Strain heterogeneity and the production of coarse grains in mechanically alloyed iron-based PM2000 alloy. Materials Science and Engineering A316(1-2), 161-165, http://dx.doi.org/10.1016/S0921-5093(01)01234-5.

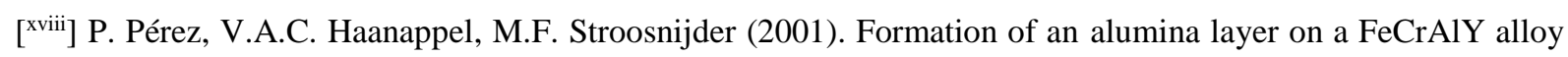
by thermal oxidation for potential medical implant applications. Surface and Coatings Technology 139, 207-215, http://dx.doi.org/10.1016/S0257-8972(00)01169-5.

$\left.{ }^{[\mathrm{xix}}\right]$ P.A. Molian, Y.M. Yang, P.C. Patnaik (1992). Laser welding of oxide dispersion-strengthened alloy MA754. Journal of Materials Science 27, 2887-2694, http://dx.doi.org/10.1007/BF00540691.

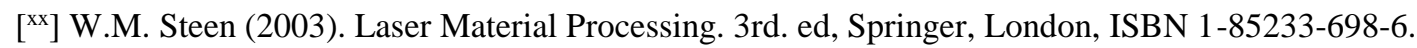

[ $\left.{ }^{\mathrm{xx}}\right]$ T.J. Kelly (1979). Pulsed YAG laser welding of ODS alloys. AIP Conference Proceedings 50(1), 215-220, ISSN 03066452.

[ ${ }^{x x i i}$ H. Hügel, T. Graf (2009). Fluidmechanische Effekte im Schmelzbad (in German). In: Laser in der Fertigung, 2nd ed., Vieweg+Teubner, Wiesbaden, 230-241, ISBN 978-3-8351-0005-3.

[ ${ }^{\text {xxiii] }}$ T. Boegelein, S.N. Dryepondt, A. Pandey, K. Dawson, G.J. Tatlock (2015) Mechanical Response and Deformation Mechanisms of Ferritic Oxide Dispersion Strengthened Steel Structures Produced by Selective Laser Melting. Acta Materialia, 87, 201-215, http://dx.doi.org/10.1016/j.actamat.2014.12.047.

$\left.{ }^{\left[{ }^{\mathrm{xxiv}}\right]}\right]$ J.C. Walker, K.M. Berggreen, A.R. Jones, C.J. Sutcliffe (2009). Fabrication of Fe--Cr--Al Oxide Dispersion Strengthened PM2000 Alloy Using Selective Laser Melting. Advanced Engineering Materials 11(7), 541-546, http://dx.doi.org/10.1002/adem.200800407.

$\left.{ }^{\left[{ }^{\mathrm{xx}}\right]}\right]$ T. Boegelein, A.R. Jones, A. Rao, G.J. Tatlock (2011). Selective laser melting of oxide dispersion strengthened steels. In: ASME 2011 Pressure Vessels and Piping Conference: Vol. 6, parts A and B, 19-28, ISBN 978-0-7918-4456-4.

[ $\left.{ }^{\mathrm{xxvi}}\right]$ T. Boegelein, G.J. Tatlock (2012) Oxidation of Oxide Dispersion Strengthened Alloy Coatings Produced by Selective Laser Melting. Proceedings of the International Symposium on High-Temperature Corrosion and Protection of Materials, HTCPM 2012, Les Embiez, France, 20-25 May 2012, paper 114.

${ }^{\left.{ }^{x x v i i}\right] ~ T . ~ B o e g e l e i n ~(2014) . ~ S e l e c t i v e ~ l a s e r ~ m e l t i n g ~ o f ~ a ~ f e r r i t i c ~ o x i d e ~ d i s p e r s i o n ~ s t r e n g t h e n e d ~ s t e e l . ~ P h . D . ~ t h e s i s, ~}$ University of Liverpool.

[ ${ }^{\text {xxviii] }}$ R.M. Hunt, K.J. Kramer, B. El-Dasher (2015). Selective laser sintering of MA956 oxide dispersion strengthened steel. Journal of Nuclear Materials 464, 80-85, http://dx.doi.org/10.1016/j.jnucmat.2015.04.011.

${ }^{\text {[xix }}{ }^{[}$R. Li, J. Liu, Y. Shi, L. Wang, W. Jiang (2012). Balling behavior of stainless steel and nickel powder during selective laser melting process. International Journal of Advanced Manufacturing Technology 59(9-12), 1025-1035, http://dx.doi.org/10.1007/s00170-011-3566-1. 
${ }^{\left[{ }^{\mathrm{xx}}\right]}$ S. Weinbruch, A. Anastassiadis, H.M. Ortner, H.P. Martinz, P. Wilhartitz (1999). On the Mechanism of High-Temperature Oxidation of ODS Superalloys: Significance of Yttrium Depletion Within the Oxide Scales. Oxidation of Metals 51(1,2), 111-128, http://dx.doi.org/10.1023/A:1018806319821.

[ ${ }^{\text {xxxi] }}$ K.E. Dawson, G.J. Tatlock, K. Chi, P. Barnard (2013). Changes in Precipitate Distributions and the Microstructural Evolution of P24/P91 Dissimilar Metal Welds During PWHT. Metallurgical and Materials Transactions A 44A, 5065-5080, http://dx.doi.org/10.1007/s11661-013-1880-y.

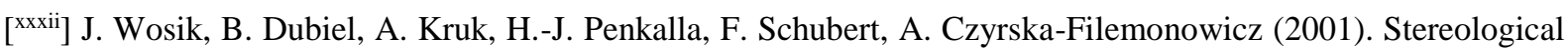
estimation of microstructural parameters of nickel-based superalloy Waspaloy using TEM methods. Materials Characterization 46, 119-123, http://dx.doi.org/10.1016/S1044-5803(01)00112-7.

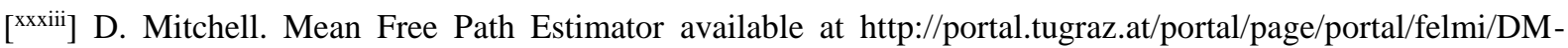
Script/DM-Script-Database, date of access: 28/01/2015.

$\left.{ }^{\text {[xxiv }}\right]$ T. Malis, S.C. Cheng, R.F. Egerton (1988). EELS log-ratio technique for specimen-thickness measurement in the TEM. Journal of Electron Microscopy Technique 8(2), 193-200, ISSN 07410581.

$\left.{ }^{\left[{ }^{x x x}\right]}\right]$ D. Tyutyunnikov, V.B. Özdöl, C.T. Koch (2015). Simultaneous orientation and thickness mapping in transmission $\quad$ electron $\quad$ Ultramicroscopy $\quad$ 150, 37-43, http://dx.doi.org/10.1016/j.ultramic.2014.11.034.

[ ${ }^{\text {xxxvi }] ~ B . ~ C h a l m e r s ~(1964) . ~ M i c r o s c o p i c ~ H e a t ~ F l o w ~ C o n s i d e r a t i o n s . ~ I n: ~ P r i n c i p l e s ~ o f ~ S o l i d i f i c a t i o n . ~ W i l e y, ~ N e w ~}$ York, 91-125, ISBN 978-0471143253.

[ ${ }^{\text {xxxvii] }}$ O. Yamaguchi, K. Matui, K. Shimizu (1985). Formation of $\mathrm{YAIO}_{3}$ with Garnet structure. Ceramics International 11(3), 107-108, http://dx.doi.org/10.1016/0272-8842(85)90006-9.

[ ${ }^{\mathrm{xxx} \text { viii }] ~ T . ~ T a c h i w a k i, ~ M . ~ Y o s h i n a k a, ~ K . ~ H i r o t a, ~ T . ~ I k e g a m i, ~ O . ~ Y a m a g u c h i ~(2001) . ~ N o v e l ~ s y n t h e s i s ~ o f ~} \mathrm{Y}_{3} \mathrm{Al}_{5} \mathrm{O}_{12}$ (YAG) leading to transparent ceramics. Solid State Communications 119, 603-606, http://dx.doi.org/10.1016/S0038-1098(01)00293-9.

[ $\left.{ }^{\text {xxix }}\right]$ J. Wunder (1997). Mikrostrukturelle Beschreibung der Warmfestigkeit ferritischer Superlegierungen (in German), VDI, Reihe 5: Grund- und Werkstoffe, Nr. 510, ISBN 3-18-351005-7.

$\left.{ }^{[\mathrm{xl}}\right]$ C.Hin, B.D. Wirth, J.B. Neaton (2009). Formation of $\mathrm{Y}_{2} \mathrm{O}_{3}$ nanoclusters in nanostructured ferritic alloys during isothermal and anisothermal heat treatment: A kinetic Monte Carlo study. Physical Review B Condensed Matter and Materials Physics 80(13), Article number 134118.

[ $\left.{ }^{x l i}\right]$ G.B. Schaffer, M.H. Loretto, R.E. Smallman, J.W. Brooks (1989). The stability of the oxide dispersion in INCONEL alloy MA6000. Acta Materialia 37(9), 2551-2558, http://dx.doi.org/10.1016/0001-6160(89)90053-9.

[ ${ }^{\text {xlii] }}$ M. Klimiankou, R. Lindau, A. Möslang, J. Schröder (2005). TEM study of PM 2000 steel. Powder Metallurgy 48(3), 277-287, http://dx.doi.org/10.1179/174329005X64171.

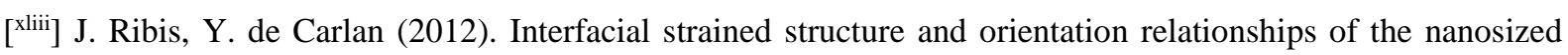
oxide particles deduced from elasticity-driven morphology in oxide dispersion strengthened materials. Acta Materialia 60, 238-252, http://dx.doi.org/10.1016/j.actamat.2011.09.042.

[xliv] M. Klimiankou, R. Lindau, A. Möslang (2004). TEM characterization of structure and composition of nanosized ODS particles in reduced activation ferritic-martensitic steels. Journal of Nuclear Materials 329-333, 347-351, http://dx.doi.org/10.1016/j.jnucmat.2004.04.083. 
${ }^{\left[{ }^{x l v}\right]}$ L. Hsiung, M. Fluss, S. Tumey, J. Kuntz, B. El-Dasher, M. Wall, B. Choi, A. Kimura, F. Willaime, Y. Serruys (2011). HRTEM study of oxide nanoparticles in K3-ODS ferritic steel developed for radiation tolerance. Journal of Nuclear Materials 409, 72-79, http://dx.doi.org/10.1016/j.jnucmat.2010.09.014.

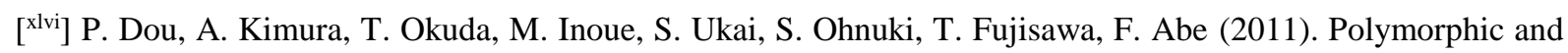
coherency transition of $\mathrm{Y}-\mathrm{Al}$ complex oxide particles with extrusion temperature in an Al-alloyed high-Cr oxide dispersion strengthened ferritic steel. Acta Materialia 59, 992-1002, http://dx.doi.org/10.1016/j.actamat.2010.10.026.

[xlvii] S. Weinbruch, A. Anastassiadis, H.M. Ortner, H.P. Martinz, P. Wilhartitz (1999). On the mechanism of high-temperature oxidation of ODS superalloys: Significance of yttrium depletion within the oxide scales. Oxidation of Metals 51(1/2), 111-128, http://dx.doi.org/10.1023/A:1018806319821.

[xlviii] E. Louvis, P. Fox, C.J. Sutcliffe (2011). Selective laser melting of aluminium components. Journal of Materials Processing Technology 211(2), 275-287, http://dx.doi.org/10.1016/j.jmatprotec.2010.09.019.

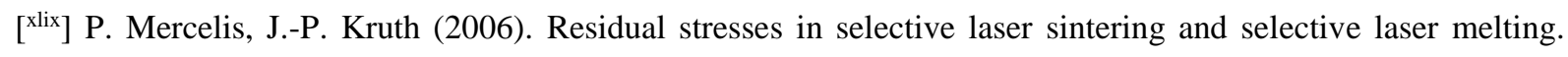
Rapid Prototyping Journal 12(5), 254-265, http://dx.doi.org/10.1108/13552540610707013.

[1] M. Shiomi, K. Osakada, K. Nakamura, T. Yamashita, F. Abe (2004). Residual stress within metallic model made by selective laser melting process. CIRP Annals - Manufacturing Technology 53(1), 195-198, ISSN 00078506 .

${ }^{[l i]}$ E. Amsterdam, G.A. Kool (2009). High cycle fatigue of laser beam deposited Ti-6Al-4V and Inconel 718, Proc. ICAF 2009, 1261-1274. http://dx.doi.org/10.1007/978-90-481-2746-7_71.

[lii] L.N. Carter, C. Martin, P.J. Withers, M.M. Attallah (2014). The influence of the laser scan strategy on grain structure and cracking behaviour in SLM powder-bed fabricated nickel superalloy. Journal of Alloys and Compounds 615, 338-347, http://dx.doi.org/10.1016/j.jallcom.2014.06.172.

[iii] T. Etter, M. Konter, M. Hoebel, J. Schurb (2014). Method for manufacturing a metallic component by additive laser manufacturing, US patent No. US20140154088 A1, filing date June 5, 2014.

[iv] S. Ukai, M. Harada, H. Okada, M. Inoue, S. Nomura, S. Shikakura, K. Asabe, T. Nishida, M. Fujiwara (1993). Alloying design of oxide dispersion strengthened ferritic steel for long life FBRs core materials. Journal of Nuclear Materials 204, 65-73, http://dx.doi.org/10.1016/0022-3115(93)90200-I.

$\left.{ }^{[\mathrm{lv}}\right]$ H. Oka, M. Watanabe, S. Ohnuki, N. Hashimoto, S. Yamashita, S. Ohtsuka (2014). Effects of milling process and alloying additions on oxide particle dispersion in austenitic stainless steel. Journal of Nuclear Materials 447, 248-253, http://dx.doi.org/10.1016/j.jnucmat.2014.01.025.

[lvi] Y. Uchida, S. Ohnuki, N. Hashimoto, T. Suda, T. Nagai, T. Shibayama, K. Hamada, N. Adasaka, S. Yamashita, S. Ohstuka, T. Yoshitake (2006). Effect of minor alloying element on dispersing nano-particles in ODS steel. Materials Research Society Symposium Proceedings 981, 107-112, ISBN 978-160423427-5. 


\section{$\underline{\text { Table Captions }}$}

Table 1. The elemental composition (wt.\%) of mechanically alloyed PM2000 according to the alloy datasheet [16] (A) and according to an analysis of the powder by ICP-OES (B).

Table 2: Results of element fractions of the concentration originally included in the alloy prior to MA, present in surface nodules and inclusions within two zones in the build; values are reported as \%. 


\section{Figure Captions}

Fig. 1: The complex hexagon-in-hexagon structure connected to the substrate plate.

Fig. 2: Micrographs of the two extreme cases of the surface morphology of outer walls. There were regions ranging from a smooth finish (a) to a rough morphology (b). Also brightly appearing $\mathrm{O}, \mathrm{Al}$ and Y-rich features were apparent; examples are marked with arrows.

Fig. 3: SEM performed on the cross section of surface segregations in BSE mode (compositional contrast) in low (a) and high (b) magnification revealed a structure composed of two main types of features. EDS measurements revealed the individual elemental compositions which are similar to alumina (c) and YAG (b), respectively. Dendritic features are marked with (*) and those with a lamella-shaped appearance with $(* *)$.

Fig. 4: SEM-SE images of a typical internal crack observed in an outer wall of the hexagon structure. The images show the crack in cross section of an etched sample to reveal the microstructure (a), the fracture surface in low (b) and in high magnification (c). $\mathrm{O}, \mathrm{Al}$ and $\mathrm{Y}$-rich inclusions are marked with arrows.

Fig. 5: TEM bright field images of a sample prepared from the as-grown condition displayed in intermediate (a) and in high (b) magnification in a tilt orientation exhibiting dislocations. A high number density of small, homogeneously dispersed, precipitates was apparent. 
Fig. 6: A plot of the relative size distribution of precipitates of TEM thin foil samples in the as-grown and post-build annealed condition compared with conventionally fabricated recrystallised PM2000. $200+$ particles $>10 \mathrm{~nm}$ were analysed for each group.

Fig. 7: TEM bright field images of extracted particles prior to annealing on carbon film. The micrographs display a small particle in two different focal conditions $(a, b)$ and a section of a large particle (c). Arrows indicate different lattice orientations/spacings.

Fig. 8: Diagram showing the elemental composition of extracted dispersoids (as-grown condition) on C-film, plotted against the particle diameter (displayed as $\mathrm{Al}+\mathrm{Ti}+\mathrm{Cr}+\mathrm{Fe}+\mathrm{Y}=100$ at.\%). Part (a) displays the diameter range 5-40 $\mathrm{nm}$ and (b) displays data ranging from 40-160 $\mathrm{nm}$.

Fig. 9: TEM bright field images of a sample prepared from the annealed condition displayed in intermediate (a) and in high (b) magnification. A high number density of small homogeneously dispersed precipitates was retained.

Fig. 10: TEM bright field images of extracted particles after annealing. A small (a) and a larger (b) single-crystalline particle are displayed and a precipitate consisting of more than one crystal (c).

Fig. 11: Diagram of the elemental composition of extracted dispersoids (annealed condition) on Cfilm, plotted against the particle diameter (displayed as $\mathrm{Al}+\mathrm{Ti}+\mathrm{Cr}+\mathrm{Fe}+\mathrm{Y}=100$ at.\%). Part (a) displays the diameter range 5-40 $\mathrm{nm}$ and (b) displays data ranging from 40-160 $\mathrm{nm}$.

Fig. 12: Ti and C-rich particles extracted on amorphous $C$ film displayed in TEM-bright field mode (a) and in dark field (diffraction contrast) imaging (b).

Fig. 13: Diagram of the volume fraction of precipitates in different regions and for different conditions. Data taken from literature [xxxix] for conventionally processed PM2000 are displayed in the fine-grained $(*)$ and coarse-grained $(* *)$ condition having an average grain size of $24.7 \mu \mathrm{m}$ and $\rightarrow \infty$, respectively. 